\title{
Challenges and Opportunities of Micro and Small Enterprises Strategy in Ethiopia Urban Development: the Case of Ambo Town, Oromia Ethiopia\#
}

Yared Teshome Geneti*

\author{
Institutes of Development Studies (IDS), University of Mysore, Karnataka, India
}

\begin{abstract}
In Ethiopia, Micro and Small Enterprise (MSE) is prioritised as important means of economic diversification, job creation, income generation and equity distribution as indispensable poverty reduction sector since 2006 . Despite the great attention given to micro and small enterprises, little research exists that examines challenges and opportunities of the Sector in the implementation trajectory. With the new initiative of National Development Programme to Accelerate Sustainable Development to Eradicate Poverty (PASDEP) in 2006-2010, the government has been commencing a new Micro and Small Enterprises Development Strategy. However, the blue prints strategy would be able to prove in the process to achieve the goals and target through timely evaluation of its implementations. It has been long time and common to listen and observe complains of MSEs on the overall sectoral performance and strategic incompatibility both among the unemployed societies and existing MSEs. Based on this rationale, the study was intended to assess the challenges and opportunities of the existing MSE strategy in Ambo town. In this descriptive research primary data were collected from 135 MSEs in Ambo using stratified and purposive sampling design.
\end{abstract}

MSEs in Ambo town are facing different challenges. These challenges are identified as marketing, financial, good governance, i.e., lack of market place; inadequacy credit facilities and inefficient service delivery. The study shows that the long and delayed procedure to establish MSEs is the most common challenges observed in both the old (2006) and new (2011) strategies. These are mainly as a result of inefficient human resource capacities of the sector and cumbersome procedures of credit and saving institution in the town. Moreover, a little understanding of unemployed society on the strategy is the main gap creating misunderstandings. Findings indicated that, the above challenges are a bottle-neck to the goal set by the strategy to create jobs for unemployment and being urban base of local economic and social development. In prospect wise, the study asserted that, the 2011 strategy has been improving MSEs to have a clear definition, typical set ups and structure arrangements as enterprise. Therefore, the strategy has identified as the means to change the societal structure by creating broad local economic and social development to the extent of medium investors. Finally, promoting awareness to active unemployed citizens by giving continues capacity building for both office staff and members of enterprises, local governance reforms and the rechecking of MSE establishment procedures are important in alleviating the problems at implementation stage.

Keywords: MSE, Strategy, Urban Development

\footnotetext{
*Email:yaredwo@gmail.com

\#This is the revised and modified version of the article, presented in the $3^{\text {rd }}$ International Conference on Economic Growth and Sustainable Development, Emerging trends, SDMIMD, November 2017.
} 


\section{Introduction}

The overall aim of MSEs strategy is to decrease unemployment rate by engaging those unemployed peoples to create job for themselves. As a discrete concept, MSE has no universally accepted definition. Different conceptual frame works, and measures of sizes have been used to define at a national and international level (MOFED, 2010). The MSEs, important vehicle of socio-economic development, have been facing enormous problems despite the ongoing public reform programs (MOFED, 2015). Since, 2002 the Ethiopian government gave a special attention to urban poverty reduction designing four consecutive Poverty Reduction Strategies (PRS). The initial poverty reduction strategy was the Sustainable Development and Poverty Reduction Programme, covered the years from 2002-2005, the second, a Plan for Accelerated and Sustained Development to End Poverty (PASDEP) from 20006-2010 was also followed by the First and Second Growth and Transformation Plan (GTP I and GTP II) from 2010-2020 (MOFED, 2016).

The 2011 SME strategy in Ethiopia has revised the first MSE strategy commenced in 2006. It clearly put the typology of MSE from Sole Proprietorship and Cooperative societies to the extent of Share Company. The strategy is based on the concept of
$20 \%$ saving deposit and $80 \%$ government loan. i.e., every registered SME is expected to deposit $20 \%$ of the money that they planned to invest and $80 \%$ of the capita is provided by regional financial institutions like Oromia Credit and Saving Share Company (OCSSC), Debit Saving and Credit Association (DSCA), Amhara Saving and Credit Association (ASCA), Addis Saving and Credit (ASC), and other regional credit and Saving institutions. In conclusion, the new SME strategy is anticipated decreasing the unemployment rate and changing the local economic and social development trajectory. However, dissatisfaction and complain of the sector are becoming the issues of the day mainly on the current MSE strategy and procedures of implementations. Considering these gap, the incompatibility agendas came up with losing the target group of the Strategy plan, unemployed youth group. Therefore, this study is going to answer: What are the nature and procedure of the old (2006) and new (2011) MSEs Strategy? What are the factors causing challenges in the implementation of MSEs strategy? What basic prospective of urban MSE development are there in the existing MSEs strategy? With these in mind, the main objective of the study is to assess the challenges and opportunities of the MSEs strategy in Ethiopia Urban Area, the case of Ambo Town. With specific focus on the nature and procedure of the old (2006) and new (2011) MSEs Strategy, the Opportunities of the current

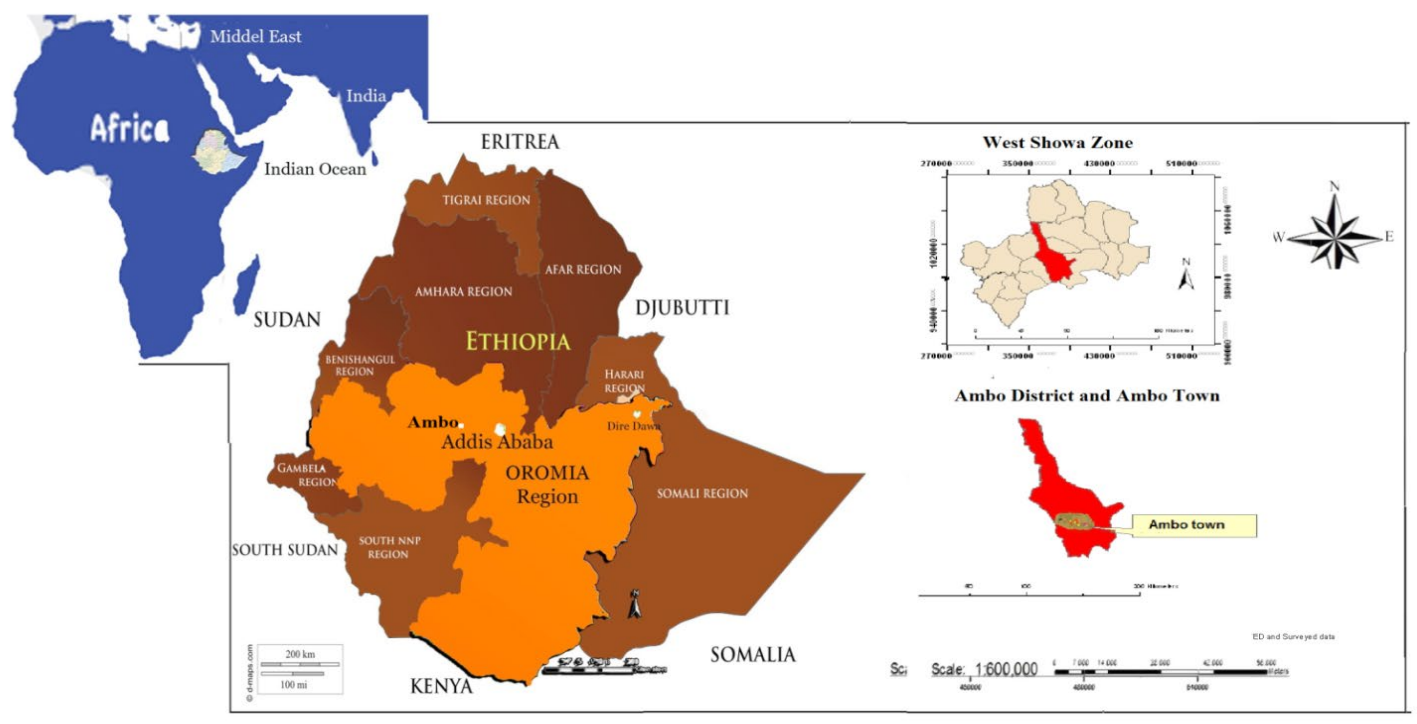

Figure 1.1 Ambo town geographic location. 
MSEs strategy in the existing urban development and factors causing challenges in the implementation of the new MSEs strategy.

\section{Delimitation/Scope of the Study}

Ambo town is located $114 \mathrm{~km}$ west of Addis Ababa, the capital of Ethiopia. Ambo is a $2^{\text {nd } ~} A$ ' grade town administrative status and the capital of West Showa Zone. The population of Ambo is more than 91,456 including the population of expansion areas (rural Localities) in 2010. The study is limited to Ambo Town Administration Office of MSEs implementation efficiencies and the office operating environment.

\section{Reviews of Related Literature}

\section{A. Conceptual Definition and Scope of Micro and small Enterprise}

Entrepreneurship is the development trajectory of creating and adding values on things by devoting the necessary time and appropriate effort assuming the accompanying financial, psychological and social risks, and receiving monetary and personal satisfaction rewards (Habtamu 2008). Another conceptual definition of entrepreneurship defines it as the process of uncovering or developing an opportunity to create value through innovation and seizing that opportunity without regard to either human and capital resources or the location of entrepreneur in a new or existing organization (Ricketts, 2017). In recent $20^{\text {th }}$ century theories of entrepreneurship, a person who creates innovations by taking calculated risks is called an entrepreneur. i.e., an entrepreneur is a person who actively looks opportunities to act and take risks of financial, psychological, and social (Boutillier, 2016). In general definitions of Micro and Small Enterprise (MSE), four basic criteria have been taken by various countries. These are: i) the head count staff/employed manpower. ii) Total and net asset and paid capital, iii) annual turnover and iv) legal entity. Although most countries definition holds the above-mentioned criteria, the countries have various criteria depending on the level of economy (Kozak, 2005). In Ethiopia various definitions of Micro and Small Enterprise are used; the 2006 strategic definition, the Central Statics Agency (CSA) basic population census definition and Definition given by the recent 2011 MSE strategy (FMSEDA, 2011).

\section{The 2006 MSE Development Strategy Definition}

Table 1.1. MSE definition from the Ethiopian context

\begin{tabular}{|l|l|c|}
\hline Sector & Manpower & A paid-up capital \\
\hline Micro enterprise & - & $<500$ USD (20,000 ET birr) \\
\hline Small enterprise & - & $<20,000$ USD (500,000 ET Birr) \\
\hline
\end{tabular}

\section{Definition of MSE given by Central Statics Agency} (CSA): the CSA definition uses employment and favors capital, intensive technologies as yardstick (FMSEDA, 2011). Accordingly, cottage and handcraft industry that performs their activities by hand and using manpower driven machines, employing less than 10 persons and using motor operated equipment are considered as small-scale manufacturing enterprises. The above definitions given by CSA, however consisted of the following short comings; it focuses on manufacturing ignoring other sectors and failure in using size of capital. Due to the absence of uniform definition of the sector, the agency failed in gathering data about cottage and handicraft industries for the last 10 years. Hence the data collected from the MSE and the ongoing strategy and support frameworks become different to analyze and to interpret in scientific ways (FMSEDA, 2011).

\section{The 2011 SME Development Strategy Definition:} is defined Based on the gathered experience, identified the gaps of the existing definition of MSE, ignoring the size of employee and by taking total asset as criteria and categorized in to industry and service sector and further it considers inflation and irregularity of currency, therefore, the improved definition is presented as follows (FMSEDA, 2011).

Table 1.2. Improved definition of 2011 MSE strategy

\begin{tabular}{|l|l|l|l|}
\hline Enterprise Level & Sector & Human power & Total asset \\
\hline Micro enterprise & Service & $\leq 5$ & $\leq 50,000(\$ 2000)$ \\
\cline { 2 - 4 } & Industry & $\leq 5$ & $\leq 100000(\$ 4000)$ \\
\hline Small enterprise & Service & $6-30$ & $\leq$ birr 500,000 (\$20000) \\
\cline { 2 - 4 } & Industry & $6-30$ & $\begin{array}{l}\leq \text { birr 1.5 million } \\
(\$ 60000)\end{array}$ \\
\hline
\end{tabular}

When ambiguity is encountered between manpower and total assets as explained above, total asset is 
taken as primary yardstick (measure) (FMSEDA, 2011).

\section{B. The Procedures of MSE Establishment}

According to the 2011 strategy and directives of Ethiopia MSE, the following procedures and criteria's; are considered as the due process of entrepreneurial set up:

- Registration for unemployment at district level,

- Passing the selection criteria to be considered as active unemployed,

- Preparing project proposal; worked jointly with local MSE office,

- Trade registration and licensing from Trade and Development office,

- Market facility; i.e., display shops or manufacturing production site,

- Starting up $20 \%$ saving to get $80 \%$ loan at regional saving and credit institutions,

- Obtaining loan based on the saved amount.

\section{The Nature of the 2006 and 2011 MSE Strategy}

The nature of the MSE strategy which distinguished the new strategy from the old one are: new definition of MSEs based on manpower and total asset, one clustered marketing and display site, saving $20 \%$ to get $80 \%$ loan, one site production and manufacturing, Lease system to buy big machineries and vehicles with payback of 40 years, tax holiday based on MSE typology and nature, persistent training and capacity building, formal accounting and auditing procedures, limited transformation period from 1-3 years, structural arrangement at district and town administration level, decreasing the minimum number of MSE to sole proprietorship and provide new MSE type like cooperative, share company and other. According to the new strategy the town administration is responsible to be considering as collateral only if the MSE members are more than 10 (FMSEDA, 2011).

On the other hand, there are special features of the 2006 MSE strategy. These are: provision of individual plots of land, the man power of MESs was not classifying MSEs based on man power from sole proprietorship to the share companies and the saving and credit financial institutions were asking for collateral on all types of SMEs.

There are also some similarities of both strategies: both are targeted at poverty redaction and intensive job creation for unemployment; there are also some similarities in procedures except saving 20\% first and all unemployed citizens above 18 years are accepted as a rightful person to form MSE (FMSEDA, 2016).

\section{Research Method}

Over the past years, there have been a number of debates on the arguments for and against a fundamental distinction between qualitative and quantitative studies to apply better in social science study. Thus, this research study employed both qualitative and quantitative research approaches quantitative nested under qualitative. The study is conducted by using descriptive survey method, in order to interpret the findings and to report the way things are done. The data collection method relied on primary data which has been collected mainly through FGDs, interviews and open and closed ended questionnaires. Secondary data are: MSEs Strategies, manuals, reports, proclamations, profiles, and statically data and other national and international reviews. There are 184 MSEs established in the Ambo town. From these MSEs 53\% (98) of them are found in one District with the total population of 478. The sample frame is those MSEs that start operation 44 out of 79 MSEs established under the 2006 strategy, 6 reformed MSEs and 8 MSE members established under the 2011 MSE strategy. And to get sample unit from different strata of MSEs, purposive and stratified sampling are applied. The stratification is proper because the sample frame for which a sample is to be drawn constitutes a heterogeneous in typology (Kothari 2004).

Therefore, the estimated characteristics of target population (p) is $0.60(\mathrm{P}=60 \%)$ are MSEs that start operation that is, more than half of the total MSEs established. Therefore, if $\mathrm{p}$ is $0.60, \mathrm{q}=1-\mathrm{p}=0.40$, with $95 \%$ level of confidence (1.96) and 5\% level of desire accuracy $(d=0.05) 135$ sample were taken from total 478 members of MSE in the town. Accordingly, aaccu- 
rate data collection was held using suitable instrument such as; Focus Group Discussion (FGD), interview and Questioners which can impact the results of a study and/or ultimately lead to valid results. After primary and secondary data was collected and analyzed through descriptive statistics and content analysis using tables, graphs and describes the findings.

\section{Research Finding Discussions}

\subsection{The Nature and Procedure of MSE Strategies}

Literally Strategies demonstrates the following basics to answer, how the plans will works, what aims and goals to achieve?, how it is going to be implemented?, what criteria's placed?, who are the target beneficiaries, partners and stakeholders and their contribution to the target societies. Therefore, understanding of the nature and procedure of the old (2006) and new (2011) MSE strategy has been evaluated by collecting primary data from the town MSE and MSE Office.

Identifying the awareness of MSEs members about the strategy and its process is important to know what kind of challenges facing? How they are solving? And what opportunities they found out from the strategy. According to figure 1.2 indicates, the level of their understanding about the nature and the procedure of the new MSEs strategy is deep (57\% and 62\% respectively). Whereas, the MSEs established under the new strategy are well conscious and aware of how the strategy works to benefit them. Hence, their good understanding can be considered as a great opportunity since; having knowledge about what they are doing makes it possible to be successful in the businesses they engaged in and it makes the strategic implementation easier. In contrary, the majorly of the MSE members, levels of understanding of about the nature and procedure of the previous strategy is found to be little or no (54\% and 61\% respectively). Whereas the old MSEs representative in the FGD were agreed that they were not aware of how things were done even they proved that they don't have heard MSE strategy, therefore, one of these group were said:

"I was not able to understand what is all about the strategy and the procedure, I should have to follow, but, I remember that we were merely form the MSE heard the government has been giving a plot of land to contraction of shed near the main asphalt road and credit without collateral" (FGD-MSE, 2016).

The majority MSEs members, which established under the 2006 strategy, were facing a great challenge because of having a little or no understanding about the nature

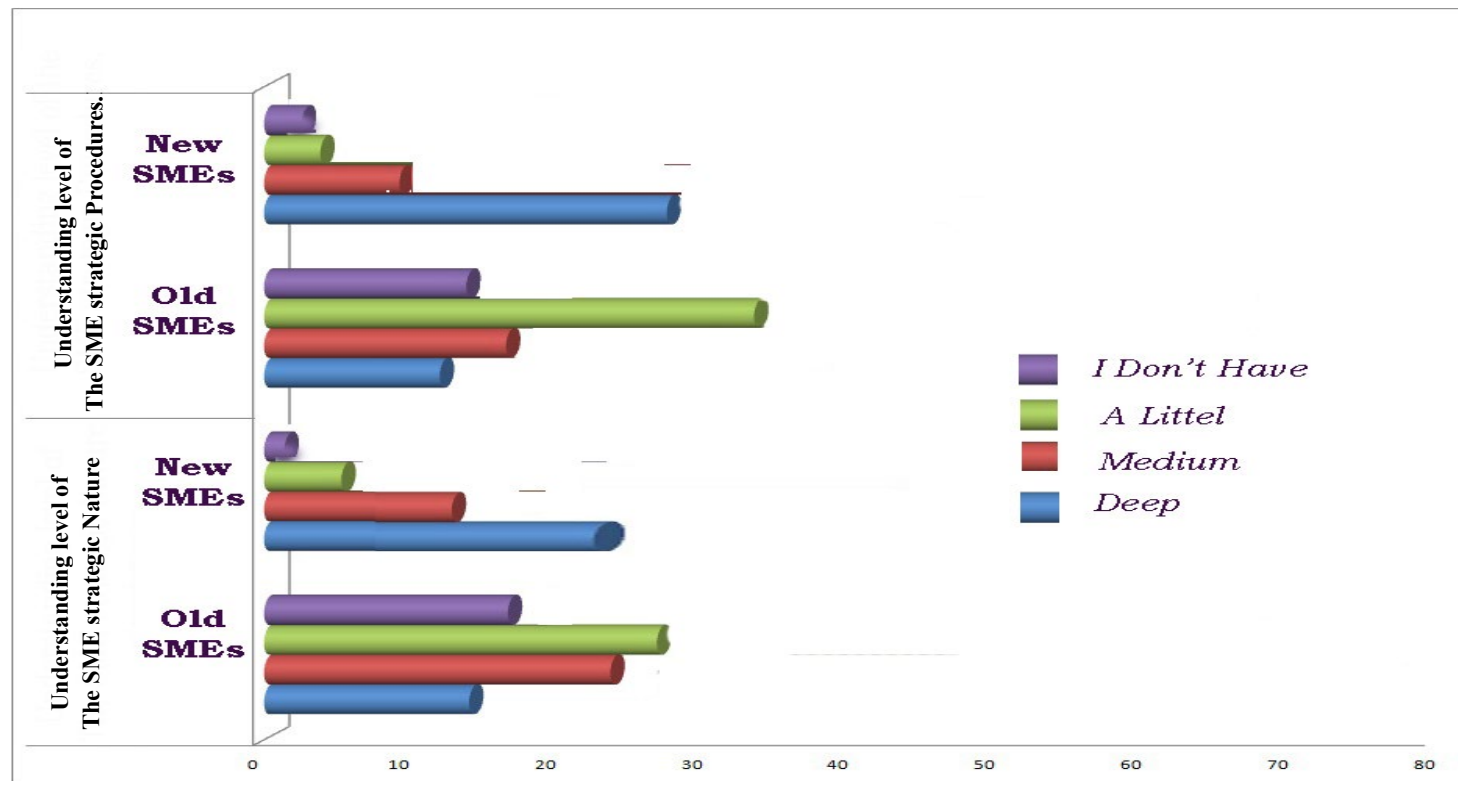

Figure 1.2 Level of understanding on the nature and procedure of New and Old strategies. 
and the procedures in the implementation of the strategy. Therefore, lack of awareness about the strategy and directives of implementation can be considered as one of the main factors causing failures to achieve MSEs strategy in Ethiopian urban development.

\subsection{The Challenges of MSE Strategy Implementations}

\section{A. The Suitability of the MSE for Unemployed Societies}

The suitability of procedure in order to create a job opportunity is evaluated according to the measurement criteria's; understanding of procedure and passion to establish MSE, good governance, how long procedures it needs and requirements to establish MSE members.

The finding for checking suitability of the MSEs strategy procedure to form MSEs indicates that the long and cumbersome procedures and lack of good governance has taken the first and second place considered as reason of unsuitability to implement the strategies. And, the requirement to establish enterprises is the lastly ranked. Unlikely, there has been a problem in requirements to establish enterprises under the old MSEs strategy implementation, therefore, the old SMEs members were ranked requirements to establish MSE as $2^{\text {nd }}$ unsuitable.

The Vice head of the MSE office was asserted that the main constraint in the unemployment side was the lack of passion to pass through the MSE formation procedures. Thus, almost one fourth $(1 / 4)$ of the registered unemployment were unable to take the trade licence of MSE. Moreover, the new MSE members in the FGD respond that though the strategy has defined the suitable procedural, but still the challenge is boring needs watching closely. Hence, one of the participants said:

"It was really boring, I have even decided to withdrawn the team and prefer to stay home ... when you passed the procedures from the District after a month, you will again faced other 'challenging home' ... the saving and credit institutions... any way I don't want to advice my friends to go through these cumbersome bureaucracy" (FGD-MSE-4, 2016).

The Town Administration the Office of Mayor (ATAOM, 2016) $3^{\text {rd }}$ quarter report on the Town Council General Assembly meeting, out of 2418 registered active unemployed from 3 districts, only $260(10.7 \%)$ were able to proceed to the selection criteria set by the strategy.

\section{B. Procedural Challenges of the New and Old Strategies}

MSEs are facing problems perhaps starting from the day of identifying the business idea to the final date of production and marketing. At the initial stage with having limited information of the Procedures to register as unemployed may considered as big challenge to the unemployed societies. Some of the common challenges

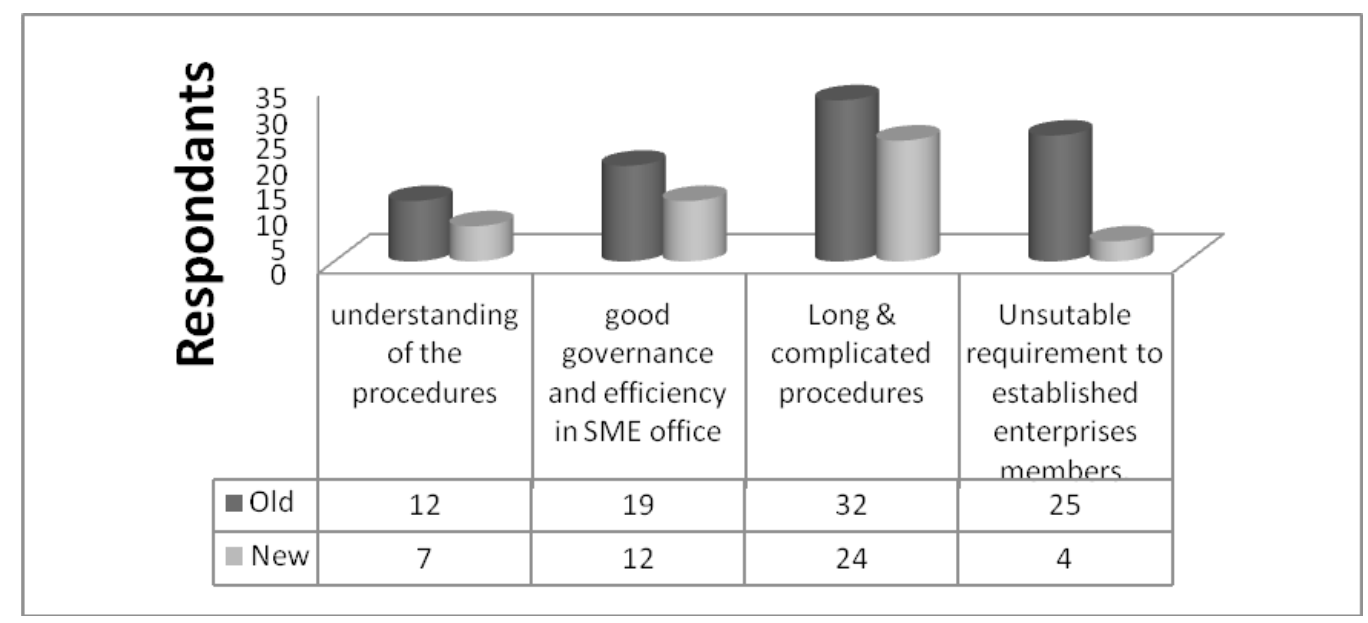

Figure 1.3 Showing the suitability of the strategy’s procedure for unemployed societies. 


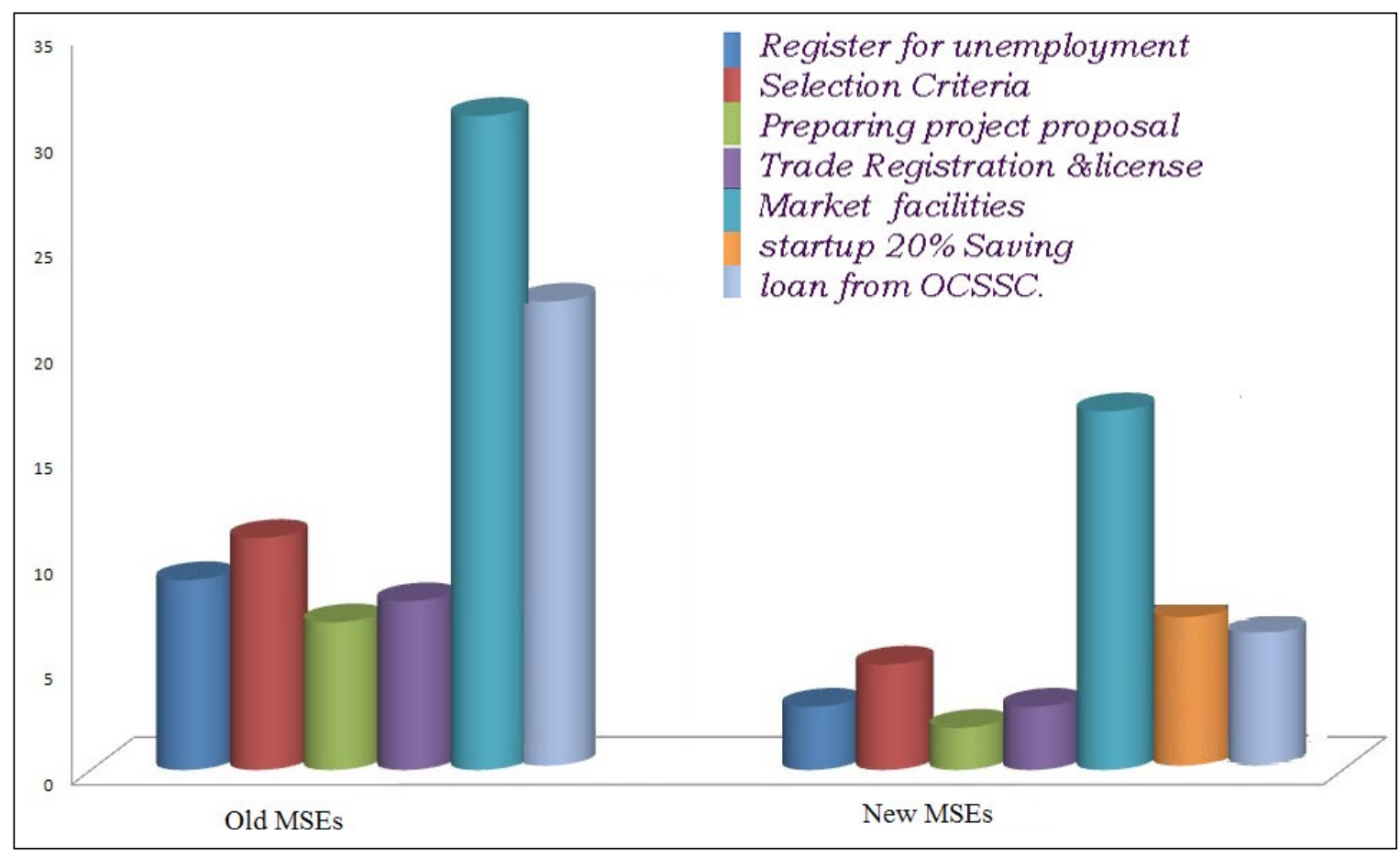

Figure 1.4 Long and delayed procedures of the New and Old Strategies implementations.

identified by the Federal MSE development Agency are challenges related to: finance supply, production and sales cluster development, industrial extension service, human resource development, technological development and growth, market and marketing system, one centre service and lack of detail understanding of MSE development package, and work commitment (FMSEDA, 2011).

The major challenge in both MSEs under 2006 and 2011 strategies was the market facility 17(36\%). According to the MSE Office, the problem of market place is still a problem in the new MSE strategy; this is because the strategy does is not allow giving a single plot of land for a MSE, but it permits a clustered production and market place which is very difficult to get plots of land for clusters at a better economic location without displacement and less budgeting for such capital investment. The town administration and the regional government budget for construction of these productions and display market place is still under way not yet finished. Secondly, SMEs under the new strategy were claim for inapplicability and lack of considering the situation of unemployment by raising the issue of starting up capital of $20 \%$ loan $9(19 \%)$ and obtaining loan from saving and credit finances. This is followed by the selection criteria $5(11 \%)$.

In 2015, the Town Administration the Agency of Land development and management have prepared 26,487 $\mathrm{m}^{2}$ plot of land for MSEs production and market place clusters. But, the Town MSEs Office had only a contractual agreement to build two clusters $(5,843$ $\mathrm{m}^{2}$ ) with the Oromia Housing Development Agency (OHDA) (ATAOM, 2015). Thus, urban local government lack of capital investment budget for building MSE cluster is still the challenge to the strategic implementation.

\section{Failure Factors Affecting the 2011 Strategy Implementation}

The factors that are used to examine the failures of the strategy implementation are, lack of understanding and negative attitude towards MSEs, lack of good governance and nepotism, inefficient service delivery and lack of unemployed society's commitment. 
Table 1.3. Challenges to the NEW Strategy implementation

\begin{tabular}{|l|l|l|l|l|}
\hline \multirow{2}{*}{$\begin{array}{l}\text { Challenges to the NEW Strategy } \\
\text { implementation }\end{array}$} & \multicolumn{4}{|l|}{ Ranking } \\
\cline { 2 - 6 } & $1^{\text {st }}$ & $2^{\text {nd }}$ & $3^{\text {rd }}$ & $4^{\text {th }}$ \\
\hline $\begin{array}{l}\text { Lack of understanding and negative attitude about } \\
\text { MSE. }\end{array}$ & & 18 & 14 & 42 \\
\hline Lack of Good Governance \&Nepotism & 59 & & & \\
\hline Inefficiency of service delivery of the MSE Office & 14 & 41 & 14 & 21 \\
\hline Lack of unemployed commitment & & 14 & 45 & 20 \\
\hline
\end{tabular}

According to Table 1.3 shows lack of good governance and nepotism $59(80 \%)$ are the most severed failure factors of implementing the strategy. Secondly, inefficient service delivery by the MSEs work division 41(56\%) was factor contributes to the challenge. The third causal factor is lack of unemployed society's commitment $45(61 \%)$ to engage in to work. Finally, lack of understanding and negative attitude to the MSEs $42(58 \%)$ is the last causal factor.

As the head of the Mayor Office says; "issues related to MSE in the Ambo town are at the post and admits the urban good governance challenges as a result of high urbanization (Rural-urban migration) and unemployment rate.... and promising to see the service delivery and good governance of MSE offices at the district and town levels based on the Civil Service Reform underway. As a result, the MSEs in our town are also exposed to the sense of rent seeking attitude and dependence syndrome to illegal benefits from government purchase, Lose control with having bookkeeping, present/submit audit report and with VAT and paying tax." (Mayor Office 2016)
Moreover, from those factors affecting implementation of the new MSES strategy in the service deliver process are; accountability, speedy service delivery, transparency, fairness and capability of the MSES work divisions.

Therefore, the proportion of being low level of satisfaction is observed in all service delivery efficiencies. Specially, it indicates that there is lack of capability and fairness of the service delivery. This indicates that the members of MSEs are considering the MSE staff at the Town and district levels are inefficient to give appropriate service with low expectation and perceives even if they give the service it is not fairly and full of favouritism. Thus, the members of the MSEs established under the new strategy are not fully satisfied by the service delivery of the MSEs work staffs which can be seen as one cause of challenges to the implementation of the strategy.

\subsection{Opportunities of the MSE Strategy}

There are better opportunities gave the space to absorbing unemployment through job creations in Ethiopian urban development. These are like government funded financial institutions to give $80 \%$ credit capital with and without collateral, high government subsidies for constructions of agglomerated market places and clustered production, special support of MSEs on creating business network and value chain management, tax incentives for MSE both at domestic and export market (tax holidays), long Payback

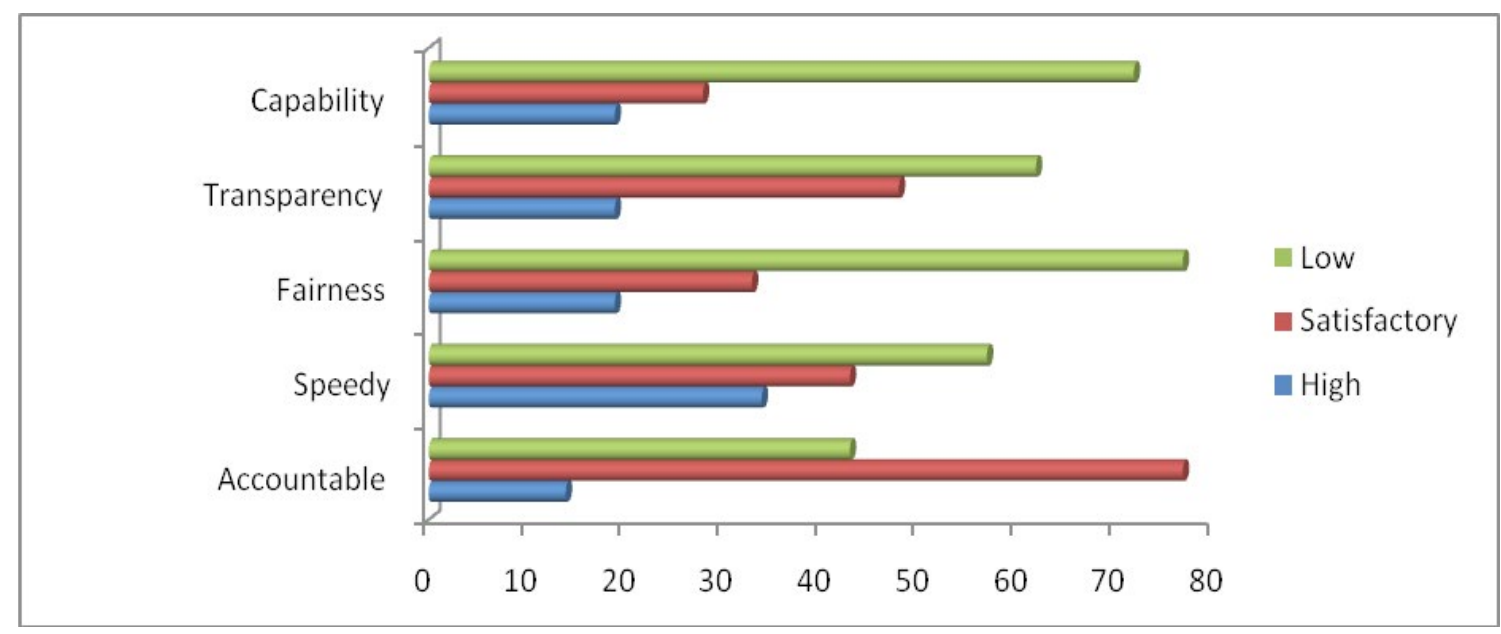

Figure 1.5 The efficiency of service delivery to MSEs. 
period for loan and affirmative action on government procurements are some of the opportunities MSEs are favoured.

Table 1.4. The Opportunity and suitability of the new MSE strategy

\begin{tabular}{|l|l|l|l|l|}
\hline \multirow{2}{*}{ Opportunities } & \multicolumn{2}{|l|}{$\begin{array}{l}\text { Better } \\
\text { Opportunities }\end{array}$} & \multicolumn{2}{l|}{ Suitable Opportunity } \\
\cline { 2 - 5 } & $\begin{array}{l}\text { No, of } \\
\text { resp. }\end{array}$ & $\begin{array}{l}\text { No, Resp. } \\
(\%)\end{array}$ & $\begin{array}{l}\text { No, of } \\
\text { resp. }\end{array}$ & $\begin{array}{l}\text { No, Resp. } \\
(\%)\end{array}$ \\
\hline $\begin{array}{l}\text { Having different types of trade } \\
\text { license }\end{array}$ & 15 & 11 & 5 & 4 \\
\hline Saving first 20\% to get loan & 53 & 39 & 18 & 13 \\
\hline $\begin{array}{l}\text { Short and clear procedure of } \\
\text { enterprises establishment and } \\
\text { loan }\end{array}$ & 19 & 14 & 29 & 22 \\
\hline $\begin{array}{l}\text { The restructuring of the MSE } \\
\text { Office }\end{array}$ & 43 & 32 & 49 & 36 \\
\hline $\begin{array}{l}\text { Creating a cluster production } \\
\text { and market place }\end{array}$ & 5 & 4 & 34 & 25 \\
\hline
\end{tabular}

According to the above table 1.4 , saving $20 \%$ to get $80 \%$ loan has been regarded as the best opportunity sought by the enterprises 53 (39\%) but it is not suitable to access as a result of financial limitation of saving and credit financial institutions expectation to deposit $40 \%$ from the local government and Civil Societies, $97 \%$ back payment from old customers and lack of capability of MSEs members to save $20 \%$. The restructuring of the MSE office at a District level has been selected as a second better opportunity and the first suitable opportunity to access $43(32 \%)$ and $49(36 \%)$.

Accordingly, the town MSE office experts asserted, the strategy has a lot of opportunities among others, the saving $20 \%$ to borrow $80 \%$ with cross collateral if the members are less than 10 but if it is above 10 the town Administration will be considered as collateral. The SMEs members are also obliged to take two weeks accounting and different business type based, trainings before giving the start up capital.

\section{Conclusions and Recommendations}

The MSEs established under the new strategy are well conscious and aware of how the strategy and directives is works to benefit them. Having awareness about what they are doing makes it possible to be successful in their business. In the other hand, the old MSEs lack awareness of the strategies and directives which can be considered as the failure factor to their livelihood. The MSEs strategies procedure in the job creation are also unsuitable for unemployed in which long and cumbersome procedures become the due process from registration as unemployment to the extent of production and markating both in 2006 and 2011 strategies.

Therefore, the major identified challenges which needs a due concern of the demand and supply sides are; the long and full of delayed procedures under the MSEs procedure to get market facility, obtaining loan from financial institutions, passing selection criteria, preparing project proposal, trade registration and licensing and registration for unemployment. Other factors affecting the strategy are the inefficiency of the service delivery by the SME office. Lack of good governance and nepotisms are the most severed failure factor of the strategy implementation. Secondly, inefficient service delivery by the MSEs work division is the factor contributes to the challenge. Lack of unemployed society's commitment and lack of understanding and negative attitude to the MSEs are the demand side failure factors. Therefore, the members of the MSEs established under both strategies are not fully satisfied by the service delivery of the MSEs work staffs which can be seen as one cause of challenges to the implementation of the strategy.

The new MSE strategy is also give more opportunities to the newly formed MSEs and the old MSEs some of these strategic opportunities are: having different types of trade license, saving first $20 \%$ to get loan from saving and credit financial institutions, clear typology and directives of procedure for enterprises establishment and loan provision, the new structural adjustment of urban SME Office at district level, Creating a suitable cluster production and market place.

To sum up, the Ethiopian MSE strategy implementation is in needs of concern of all stake holders; the urban authorities, experts, the unemployed society and the entrepreneur themselves. Hence, Ambo town MSEs are in gloom stage and needs urgent interventions to solve the long existing challenges. And the 
lion share goes to the government to give due attention to curb the good governance and financial challenge at all MSEs Procedures and stages of development.

This study has also made appropriate and constructive recommendations to urge the concerned body to take corrective measures sooner than later. Promoting the Awareness of active unemployment and all MSEs about the Procedures, Opportunity and challenges in local economy and social development, Giving persistent capacity building package on basic knowledge on book keeping and business skill that help enterprise to manage effectively and training to the MSE office Experts, Promoting good governance to change this sector susceptibility to lack of good governance and Nepotism and Rechecking the procedure to solve the financial constraint on the basis of their business nature, credit amount and time.

\section{Bibliography}

Ambo Town Administration the Office of Mayor (ATAOM). (2016). Annual Performance Report for Town Council. Ambo town, Unpublished.

Ambo Town MSE Office (ATMSEO). (2016). The third quarter performance report. Ambo, Unpublished.

Boutillier, S. (2016). The theory of the entrepreneur: from heroic to socialised entrepreneurship.

Civil Service and Good Governance Office (CSGGO). (2016). The third quarter human resource report. Ambo, Unpublished.

Economic Commission for Africa (ECA). (2001). Enhancing the Competitiveness of Small and Medium Enterprises in
Africa: A Strategic Framework for Institutional Support. A. A. Ethiopia.

European Commission (EU). (2003). Definition of micro, small and medium-sized enterprises. Official Journal of the European Union.

Federal MSE Development Agency (FMSEDA). (2011). Ethiopian Cities Job Creation Best Experian's. Ethiopian City Day Central Committee Mekele, Tigray.

Federal MSE Development Agency (FMSEDA). (2011). Improved MSE strategy of 2011. A. A. Ethiopia.

Federal MSE Development Agency (FMSEDA). (2005). MSE strategy of 2006. A. A. Ethiopia.

Gray, E. (2004). Doing Research in the Real World. SAGE Publications, London.

Habtamu, T. (2008). Challenges and Opportunities of Small and Medium Scale Enterprises (SMEs) in kolfe Sub-city Addis Ababa. A. A. Ethiopia.

Kothari, C. R. (2004). Research Methodology. Methods and Technique, $2^{\text {nd }}$ revised Edition.

Kozak, M. (2005). International Finance Corporation (IFC). Washington, D.C.

Ministry of Finance and Economic Development. (2005). Plan for Accelerated and Sustained Development to End Poverty (PASDEP). A. A. Ethiopia.

Ministry of Federal Finance and Economic Development. (2010). Growth and Transformation Plan I. A. A. Ethiopia. Ministry of Federal Finance and Economic Development. (2015). Growth and Transformation Plan I. A. A. Ethiopia Oromia Credit \& Saving Share Company (OCSSC). (2016). The third quarter reports. Ambo city council.

Ricketts, M. (2017). Theories of Entrepreneurship: Historical Development and Critical Assessment. The Oxford Handbook of Entrepreneurship.

United Nations (2009). Implementation of the International Covenant on Economic, Social and Cultural Rights, E/C.12/ETH/1-3 